\title{
Clinical features and therapeutic management of patients admitted to Italian acute hospital psychiatric units: the PERSEO (psychiatric emergency study and epidemiology) survey
}

\author{
Andrea Ballerini ${ }^{1}$, Roberto M Boccalon ${ }^{2}$, Giancarlo Boncompagni ${ }^{3}$, \\ Massimo Casacchia ${ }^{4}$, Francesco Margari ${ }^{5}$, Lina Minervini ${ }^{6}$, Roberto Righi ${ }^{7}$, \\ Federico Russo ${ }^{8}$, Andrea Salteri ${ }^{9}$, Sonia Frediani10, Andrea Rossi*10, \\ Marco Scatigna ${ }^{10}$ and the PERSEO study group ${ }^{11}$
}

\begin{abstract}
Address: ${ }^{1}$ Servizio Psichiatrico Diagnosi e Cura, Santa Maria Nuova Hospital, Firenze, Italy, ${ }^{2}$ Servizio Psichiatrico Diagnosi e Cura, Sant' Anna Hospital, Ferrara, Italy, ${ }^{3}$ Servizio Psichiatrico Diagnosi e Cura, S. Orsola Malpighi Hospital, Bologna, Italy, ${ }^{4}$ Clinica Psichiatrica, San Salvatore Hospital, L'Aquila, Italy, ${ }^{5}$ Istituto di Clinica Psichiatrica, Policlinico Consorziale Hospital, Bari, Italy, ${ }^{6}$ Dipartimento di Salute Mentale, Azienda USL 16 Hospital, Padova, Italy, 7 Servizio Psichiatrico Diagnosi e Cura, Hospital of Adria, Rovigo, Italy, ${ }^{8}$ Servizio Psichiatrico Diagnosi e Cura, Nuovo Regina Margherita Hospital, Roma, Italy, ${ }^{9}$ Servizio Psichiatrico Diagnosi e Cura, Vimercate Civil Hospital, Milano, Italy, ${ }^{9} \mathrm{Medical}$ Department, Eli Lilly Italia, Firenze, Italy and ${ }^{11}$ See Appendix for details of participating groups

Email: Andrea Ballerini - ballerini.ciardi@libero.it; Roberto M Boccalon - rmboccalon@tin.it;

Giancarlo Boncompagni - giancarlo.boncompagni@ausl.bo.it; Massimo Casacchia - massimo.casacchia@cc.univaq.it;

Francesco Margari - margari.f@psichiat.uniba.it; Lina Minervini - lina.minerva@libero.it; Roberto Righi - righi.roberto@libero.it;

Federico Russo - federusso@libero.it; Andrea Salteri - andreasalteri@mac.com; Sonia Frediani - frediani_sonia@lilly.com;

Andrea Rossi* - rossi_andrea_a@lilly.com; Marco Scatigna - scatigna_marco@lilly.com; the PERSEO study group - ballerini.ciardi@libero.it

* Corresponding author
\end{abstract}

Published: 5 November 2007

Annals of General Psychiatry 2007, 6:29 doi:10.1186/1744-859X-6-29
Received: 14 May 2007

Accepted: 5 November 2007

This article is available from: http://www.annals-general-psychiatry.com/content/6/I/29

(C) 2007 Ballerini et al; licensee BioMed Central Ltd.

This is an Open Access article distributed under the terms of the Creative Commons Attribution License (http://creativecommons.org/licenses/by/2.0), which permits unrestricted use, distribution, and reproduction in any medium, provided the original work is properly cited.

\begin{abstract}
Background: The PERSEO study (psychiatric emergency study and epidemiology) is a naturalistic, observational clinical survey in Italian acute hospital psychiatric units, called SPDCs (Servizio Psichiatrico Diagnosi e Cura; in English, the psychiatric service for diagnosis and management). The aims of this paper are: (i) to describe the epidemiological and clinical characteristics of patients, including sociodemographic features, risk factors, life habits and psychiatric diagnoses; and (ii) to assess the clinical management, subjective wellbeing and attitudes toward medications.

Methods: A total of 62 SPDCs distributed throughout Italy participated in the study and 252I patients were enrolled over the 5 -month study period.

Results: Almost half of patients (46\%) showed an aggressive behaviour at admission to ward, but they engaged more commonly in verbal aggression (38\%), than in aggression toward other people (20\%). A total of $78 \%$ of patients had a psychiatric diagnosis at admission, most frequently schizophrenia (36\%), followed by depression (16\%) and personality disorders (14\%), and no relevant changes in the diagnoses pattern were observed during hospital stay. Benzodiazepines were the most commonly prescribed drugs, regardless of diagnosis, at all time points. Overall, up to $83 \%$ of patients were treated with neuroleptic drugs and up to $27 \%$ received more than one neuroleptic either during hospital stay or at discharge. Atypical and conventional antipsychotics were equally prescribed for schizophrenia ( 59 vs $65 \%$ during stay and 59 vs $60 \%$ at discharge), while
\end{abstract}


atypical drugs were preferred in schizoaffective psychoses (72 vs $49 \%$ during stay and 70 vs $46 \%$ at discharge) and depression ( $4 \mathrm{I}$ vs $32 \%$ during stay and 44 vs $25 \%$ at discharge). Atypical neuroleptics were slightly preferred to conventional ones at hospital discharge (52 vs $44 \%$ ). Polypharmacy was in general widely used. Patient attitudes toward medications were on average positive and selfreported compliance increased during hospital stay.

Conclusion: Results confirm the widespread use of antipsychotics and the increasing trend in atypical drugs prescription, in both psychiatric in- and outpatients.

\section{Background}

Several countries, mainly in North America and Europe, have adopted psychiatric units into general hospitals, as an alternative to the classic psychiatric hospital, for referral of acute patients with mental illnesses. In Italy, since 1978 , the law prescribes that psychiatric patients can only be admitted to hospitals through these specific emergency structures, called SPDCs (Servizio Psichiatrico Diagnosi e Cura, i.e. psychiatric service for diagnosis and management). The implementation of this mental health reform law shifted the focus of care from mental hospitals to community services. Since their institution, patients remain in SPDCs only during the acute phase of their illness. At discharge, they usually receive therapeutic prescriptions and are no longer followed by SPDC structures, but by territorial services (some of which are specialized on, e.g., drug addiction, etc), which are not part of the general hospital system [1]. SPDCs should be the perfect setting for studying psychiatric patients at their hospital presentation, however bed shortages, emphasis on acuity and a continuous emergency situation render it rather difficult to implement clinical research and epidemiology programs.

In order to study, from an epidemiological perspective, the Italian population referring to psychiatric emergency structures, the PERSEO project - for psychiatric emergency study and epidemiology - was designed. The whole project consisted of two phases: a pilot phase involving 15 SPDCs, performed in 2002, called the EPICA study (for epidemiology in psychiatry: acute cases), which collected preliminary epidemiological information and validated in Italian the Modified Overt Aggression Scale (MOAS) and the Nurses' Observational Scale for Inpatient Evaluation (NOISIE) [2]. The second phase consists of the PERSEO study, a larger observational multi-centre study involving 62 Italian SPDCs, aimed at assessing the sociodemographic and clinical characteristics of patients, their pathways to psychiatric admission, and describing their behaviour, subjective wellbeing, management and attitude towards treatment during SPDC stay. Study characteristics and methods have been described in depth in a previous paper [3]. We were also interested in evaluating the possible differences between first admission versus repeated admission patients, also referring to data specifi- cally concerning first admission patients and their aggressive behaviour, which have recently been the object of a specific publication [4]. The present paper focuses mainly on the management of SPDC patients and their attitudes towards pharmacological treatments.

\section{Methods}

PERSEO was designed as a cross-sectional observational multi-centre study aimed at assessing some epidemiological features of patients referring to Italian SPDCs, and in particular their overall management and psychopharmacological treatment in the emergency setting. A total of 62 SPDCs, distributed throughout Italy, participated in the study. Following approval by the Ethics Committees of the participant institutions and obtainment of the patients' written informed consent, all consecutive subjects aged 18 years or more admitted to an SPDC between September 2003 and April 2004 were enrolled into the study. All patients were admitted to the study only once over the enrolment period. The subjects were evaluated at admission, and then daily for the first 3 days of hospital stay and at discharge or at day 30 , whichever came first.

Psychiatric symptoms were evaluated by the 24 items Brief Psychiatric Rating Scale (BPRS) [5] and the Brief Symptoms Inventory (BSI) [6]. The patients' subjective wellbeing was assessed by the Subjective Wellbeing under Neuroleptics (SWN) scale [7], while the Drug Attitude Inventory (DAI-30) [8] was used to measure their attitude towards the pharmacological treatments. The DAI-30 is a relatively widely used self-report inventory that focuses on the subjective effect of antipsychotic medications. To assess the prevalence of aggressive behaviours, the Modified Overt Aggression Scale (MOAS) [9], which is the modified version of the Overt Aggression Scale (OAS), developed by Yudofski et al [10] and recently validated in Italian by Margari et al [2], was used.

Sociodemographic and anamnestic data, life habits, risk factors for psychiatric disease, reason for hospital admission, referring structure, clinical and psychometric evaluations, concomitant diseases, previous and ongoing psychiatric treatment, admission and discharge diagnoses, and treatments administered in SPDC were recorded on 
case record forms (CRF). For a full statistical analysis, patient diagnoses were grouped as described in Table 1.

Project and data management, and statistics were conducted by MediData Studi e Ricerche. Data were analyzed using SAS for Windows, release 8.2 (The SAS Institute Inc.). All quantitative variables were described by means, standard deviations and ranges. Absolute and relative frequency distributions were given for qualitative variables. Comparisons were performed by Student's $t$ test for mean values, chi-square test, or Fisher exact test. When multiple comparisons were performed, Bonferroni's correction was taken into account. More details on the methodology of the study can be found in Ballerini et al 2005 [4].

\section{Results}

Overall, 2521 patients were enrolled in the 62 participating SPDCs, with a consequent guarantee of a generous geographic coverage of the country. As 49 patients were not viable due to protocol violations or missing data, the analyses were conducted on 2472 patients $(98.1 \%)$. Their sociodemographic characteristics are summarized in Table 2. Mean age was significantly higher among women than men $(\mathrm{p}<0.001)$. The percentage of smokers and alcohol or drug abusers was significantly higher in men ( $\mathrm{p}$ $<0.001$ ). Admission was voluntary in $85 \%$ of cases, involuntary in the remaining $15 \%$ of cases; a significantly higher percentage of women than men were voluntary admitted ( $p<0.001)$. In addition, marital and occupational status results were distributed in a statistically different manner between males and females $(p<0.001)$.

A total of 772 (31.2\%) patients were referred by specialized structures, either private psychiatrists or public mental health centres, $362(14.6 \%)$ by non-specialized health professionals (general practitioners or physicians operating in emergency structures), 340 (13.8\%) by other hospitals or rehabilitation structures, while the majority of patients $(998 ; 40.4 \%)$ had not contacted a physician before admission to an SPDC. Among the reasons for admission, poor compliance to psychopharmacological treatment was reported in $44.9 \%$ of the overall study population and in $52.2 \%$ of subjects presenting with severe psychiatric symptoms.

A total of 542 (21.9\%) patients had no diagnosis at admission. The diagnoses of the remaining 1930 patients (78.1\%) are summarized in Table 3 (lefthand column). At discharge from the SPDC, a psychiatric diagnosis had been established in almost all patients $(n=2407 ; 97.4 \%)$. The distribution of diagnoses at discharge results were higher in women than in men for affective diseases and neurotic disorders, while schizophrenia and substance abuse were more often diagnosed in men than women (Table 3, righthand columns).
Table I: Diagnosis grouping by ICD9-CM code

\begin{tabular}{|c|c|}
\hline Diagnosis group & ICD9-CM CODES \\
\hline Schizophrenia & 295/295.xx (not 295.7) schizophrenia \\
\hline \multirow{6}{*}{$\begin{array}{l}\text { Paranoid status and other } \\
\text { non-organic psychoses }\end{array}$} & 297/297.xx Paranoid status \\
\hline & 298.2 Reactive confusional status \\
\hline & $\begin{array}{l}298.3 \text { Acute paranoid reaction } \\
\text { (delirious bouffee) }\end{array}$ \\
\hline & 298.4 Psychoenic paranoid psic. \\
\hline & 298.8 Other reactive psychoses \\
\hline & 298.9 SAI psychoses \\
\hline \multirow{6}{*}{$\begin{array}{l}\text { Affective psychosis, manic } \\
\text { episodes, excitement status }\end{array}$} & 296.0x Single ep. mania \\
\hline & 296.Ix Recurrent ep. mania \\
\hline & 296.4x Affective bipolar sind. manic ep. \\
\hline & 296.8I Atypical manic sind \\
\hline & 296.6x Affective bipolar sind. mixed ep. \\
\hline & $\begin{array}{l}\text { 298.I Agitataed type psy.; psychogen. } \\
\text { excitat. }\end{array}$ \\
\hline $\begin{array}{l}\text { Affective psychosis, } \\
\text { depression, }\end{array}$ & 296.2 Depr. single ep. \\
\hline \multicolumn{2}{|l|}{ depressive status } \\
\hline & 296.3x Depr. recurrent ep. \\
\hline & 296.5x Bipolar affective sind. depr. ep. \\
\hline & 296.82 Atypical depression \\
\hline & 298.0 Atyp. psychosis depressive type \\
\hline & 3II.x Depression not other class. \\
\hline & $\begin{array}{l}296.7 \times \text { Manic-depr. sind circular type } \\
\text { SAI }\end{array}$ \\
\hline & $\begin{array}{l}296.8 x \text { (except } .8 I \circ .82) \text { Manic depr } \\
\text { sind SAI }\end{array}$ \\
\hline & 296.9x Affective psy. SAI \\
\hline Schizoaffective psychosis & 295.7 \\
\hline Personality disorders & $301 / 301 . x x$ \\
\hline Neurotic disorders & $300 / 300 . x x$ \\
\hline $\begin{array}{l}\text { Acute stress reactions, } \\
\text { adaptation reactions }\end{array}$ & 308/308.xx/309/309.xx \\
\hline \multirow[t]{2}{*}{ Substance abuse, dependence } & 303/303.xx/304/304.xx/305/305.xx \\
\hline & $291 / 291 . x x / 292 / 292 . x x$ \\
\hline \multirow{5}{*}{$\begin{array}{l}\text { Dementia and psycho-organic } \\
\text { syndromes }\end{array}$} & 290/290.xx dementia \\
\hline & 293.x Transient organic psychoses \\
\hline & 294/294.xx Chronic organic psychoses \\
\hline & $\begin{array}{l}3|0 / 3| 0 . x x \text { Frontal lobe synd. And } \\
\text { other non- }\end{array}$ \\
\hline & psychotic from brain damage \\
\hline \multirow{6}{*}{$\begin{array}{l}\text { Mental retardation, infantile } \\
\text { psychoses }\end{array}$} & $3|4 / 3| 4 . x x /$ Infant hypercinetc sindr. \\
\hline & $\begin{array}{l}3|5 / 3| 5 . x x / \text { Specific devlopm. } \\
\text { retardation }\end{array}$ \\
\hline & $3|7 / 3| 7 . x x /$ Mental retardation \\
\hline & $3|8 / 3| 8 . x x \mid$ \\
\hline & $319 / 319 . x x \mid$ \\
\hline & 299/299.xx Infant psychoses, autism \\
\hline \multirow[t]{8}{*}{ Others } & 302.x Sexual deviations and disturb. \\
\hline & $\begin{array}{l}\text { 306.x Physical disfunctions with psych. } \\
\text { origin }\end{array}$ \\
\hline & 307.xx (except 307.I, 307.5) \\
\hline & 307.1 anorexia \\
\hline & $307.5 x$ other alimentary disturb. \\
\hline & $3|2 / 3| 2 \cdot x x \mid$ \\
\hline & $3|3 / 3| 3 . x x \mid$ \\
\hline & 316 \\
\hline
\end{tabular}


Table 2: Sociodemographic characteristics of valuable patients $(n=2472)$

\begin{tabular}{|c|c|c|c|}
\hline Characteristic & Parameter & & \\
\hline & & Females & Males \\
\hline \multirow[t]{2}{*}{ Gender, n (\%) } & & $1214(49.1)$ & $1258(50.9)$ \\
\hline & Mean (SD) & Females & Males \\
\hline Age & 43.7 (14.2) & $45.7(14.3)^{*}$ & $41.7(13.8)^{*}$ \\
\hline $\begin{array}{l}\text { Occupational status, } \\
\text { n (\%) }\end{array}$ & Overall & Females* & Males* \\
\hline Employed & $543(22.0)$ & $225(18.5)$ & $318(25.3)$ \\
\hline Housewife & $328(13.3)$ & $325(26.8)$ & $3(0.2)$ \\
\hline Student & 47 (1.9) & $19(1.6)$ & $28(2.2)$ \\
\hline Unemployed & $658(26.6)$ & $249(20.5)$ & $409(32.5)$ \\
\hline Retired & $703(28.4)$ & $309(25.5)$ & $394(31.3)$ \\
\hline Disabled & $103(4.2)$ & $40(3.3)$ & $63(5.0)$ \\
\hline Other & $42(1.7)$ & $21(1.7)$ & $21(1.7)$ \\
\hline NA & $48(1.9)$ & $26(2.1)$ & $22(1.7)$ \\
\hline Marital status, n (\%) & Overall & Females* & Males* \\
\hline Single & $1079(43.6)$ & $385(3 \mid .7)$ & $694(55.2)$ \\
\hline Married & $564(22.8)$ & $365(30.1)$ & $199(15.8)$ \\
\hline Widow & $103(4.2)$ & $83(6.8)$ & $20(1.6)$ \\
\hline Divorced & $27 \mid(10.9)$ & $157(13.0)$ & $114(9.0)$ \\
\hline NA & $455(18.4)$ & $224(18.4)$ & $231(18.4)$ \\
\hline Life habits, $\mathbf{n}(\%)$ & Overall & Females* & Males* \\
\hline Smokers & $|42|(57.5)$ & $542(44.6)$ & 879 (69.9) \\
\hline Alcohol abusers & $462(18.7)$ & $149(12.3)$ & $313(24.9)$ \\
\hline Drug abusers & $86(3.5)$ & 15 (1.24) & $71(5.6)$ \\
\hline $\begin{array}{l}\text { Admission status, } \mathbf{n} \\
(\%)\end{array}$ & Overall & Females* & Males* \\
\hline Voluntary & $2103(85.1)$ & $1073(88.4)$ & $1030(81.9)$ \\
\hline Involuntary & $364(14.7)$ & 140 (I I.5) & $224(17.8)$ \\
\hline NA & $5(0.2)$ & $\mathrm{I}(0 . \mathrm{I})$ & $4(0.3)$ \\
\hline
\end{tabular}

*Males versus females, $\mathrm{p}<0.00 \mathrm{I}$; NA: Not available/unknown.

In total, $94 \%$ of patients $(\mathrm{n}=2325)$ were viable for the MOAS and almost half of them (46.4\%) had a MOAS score greater than 0 at admission. The aggressive behaviour recorded was most commonly a verbal one $(37.8 \%)$, while aggression against other people accounted for $20.5 \%$ of patients and aggression against property for $18.3 \%$. Auto-aggression episodes occurred in $15.7 \%$ of cases.

At admission to an SPDC, $66.3 \%$ of patients had received a previous psychopharmacological treatment, as summarized in Table 4 (lefthand column), most frequently
(73.1\%) a combination therapy; the most common combinations were antidepressants with benzodiazepines (7.4\%) and conventional antipsychotics with benzodiazepines (6.2\%). Single treatments were $9.0 \%$, and $6.8 \%$ conventional and atypical antipsychotics, $4.9 \%$ benzodiazepines, 3.4\% antidepressants, and $2.8 \%$ mood stabilizers. A psychoactive medication was administered during SPDC stay to $98.3 \%$ of patients and prescribed at discharge to $95.4 \%$ (Table 4 , middle and right columns).

Consistent with psychiatric diagnoses, antidepressants are more frequently prescribed for women than men, while antipsychotics and anticholinergics are more frequently prescribed for men at any time of data collection. Benzodiazepines were more frequently prescribed to women before SPDC admission but, during hospitalization and at discharge, this difference reduced to a non-significant level.

The psychopharmacological treatments prescribed before admission to the SPDC, during hospital stay and at discharge, stratified per psychiatric diagnosis groups, are reported in Figures 1 and 2.

The switch rates for neuroleptic therapy were analysed. Overall, 49\% of patients were taking neuroleptic drugs (either typical or atypical) and 7\% received more than one neuroleptic, before admission to hospital. After admission to an SPDC, 83\% were prescribed neuroleptic drugs and $27 \%$ had a combination of them. The prescription of atypical antipsychotics increased during SPDC stay for all diagnostic groups, slightly for schizophrenic patients $(+7 \%)$, but much more markedly for manic $(+52 \%)$ and schizoaffective $(+28 \%)$ patients. In addition, conventional antipsychotic prescriptions increased in all diagnostic groups during hospital stay, though with a slightly different pattern: from $+14 \%$ for schizophrenia up to $+45 \%$ for personality disorders. In $74.3 \%$ of the patients who were taking a combination of conventional and atypical antipsychotics at admission, the combination was confirmed during hospital stay and/or at discharge. Similarly, $64.5 \%$ and $60.6 \%$ of the patients who were taking only atypical and only conventional antipsychotics, respectively, kept on with the same treatment during hospital stay and/or at discharge. Patients who were not under neuroleptics at admission started antipsychotic therapy during hospital stay and/or at discharge, with atypical only, conventional only, both conventional and atypical drugs in $22.2 \%, 28.4 \%$, and $20.4 \%$ of cases, respectively. As shown in Figures 1 and 2, at discharge, atypical antipsychotics prescriptions were in general confirmed, while conventional antipsychotics tended to be reduced. 
Table 3: Diagnoses at admission to SPDC and at discharge. The percentage is calculated on patients with an established diagnosis at admission and at discharge.

\begin{tabular}{|c|c|c|c|c|}
\hline \multirow[t]{2}{*}{ Diagnosis } & \multirow[t]{2}{*}{ Admission n (\%) } & \multicolumn{3}{|c|}{ Discharge n (\%) } \\
\hline & & Overall & Females & Males \\
\hline $\begin{array}{l}\text { Schizophrenia, paranoid status, other non-organic } \\
\text { psychosis }\end{array}$ & $698(36.2)$ & $843(35.0)$ & $342(28.9)^{*}$ & $50 \mathrm{I}(4 \mathrm{I} .0)^{*}$ \\
\hline Affective psychosis, depression, depressive status & $315(16.3)$ & $401(16.7)$ & $246(20.8)^{*}$ & $155(12.7)^{*}$ \\
\hline Personality disorders & $268(13.9)$ & $325(13.5)$ & $174(14.7)$ & $151(12.4)$ \\
\hline Affective psychosis, manic episodes, excitement status & $176(9.1)$ & $213(8.9)$ & $121(10.2) \dagger$ & $92(7.5) \dagger$ \\
\hline Schizoaffective psychosis & $138(7.2)$ & $164(6.8)$ & $93(7.9) \dagger$ & $71(5.8) \dagger$ \\
\hline Substance abuse, dependence & $94(4.9)$ & $135(5.6)$ & $32(2.7)^{*}$ & $103(8.4)^{*}$ \\
\hline Neurotic disorders & $77(4.0)$ & $103(4.3)$ & $69(5.8)^{*}$ & $34(2.8)^{*}$ \\
\hline Dementia and psycho-organic syndromes & $43(2.2)$ & $78(3.2)$ & $36(3.0)$ & $42(3.4)$ \\
\hline Mental retardation, infantile psychoses & $29(1.5)$ & $28(1.2)$ & $9(0.8)$ & $19(1.6)$ \\
\hline Acute stress reactions, adaptation reactions & $12(0.6)$ & $47(2.0)$ & $28(2.4)$ & $19(1.6)$ \\
\hline Others/NA & $80(4.1)$ & $70(2.9)$ & $34(2.9)$ & $36(2.9)$ \\
\hline $\begin{array}{l}\text { Total no of patients with diagnosis (\% of total } \\
\text { PERSEO population) }\end{array}$ & $1930(78.1)$ & $2407(97.4)$ & II $84(97.5)$ & $1223(97.2)$ \\
\hline
\end{tabular}

*Males versus females, $\mathrm{p}<0.00 \mathrm{I} ;$ †males versus females, $\mathrm{p}<0.05$.

In general, the patients showed improvements from admission to discharge in their psychotic symptoms, as evaluated both by psychiatrists (by BPRS) and by the patients themselves (by BSI). Subjective wellbeing was evaluated on the SWN scale by 793 patients, with both admission and discharge questionnaires fully compiled. SWN was rated by all patients, either with or without antipsychotics. SWN mean total score increased from admission to discharge in all antipsychotic treatment groups: atypical only, conventional only, both conven- tional and atypical (Table 5). Overall, the patients' attitude towards neuroleptics was positive, as indicated by the high percentage of patients with a positive DAI-30 total mean score in all treatment groups at admission, which further increased at discharge (Table 5). At admission $44 \%$ of subjects were receiving psychological support or had received it within 1 month prior to admission. Psychological support was then administered to $65 \%$ of patients during hospital stay and prescribed at discharge to approximately $68 \%$ of patients.

Table 4: Psychopharmacological treatment before admission to SPDC, during SPDC stay and at discharge. Percentages are calculated on patients under treatment at admission, during hospital stay and at discharge.

\begin{tabular}{|c|c|c|c|c|c|c|c|c|c|}
\hline \multirow[t]{2}{*}{ Type of drug } & \multicolumn{3}{|c|}{ At admission $\mathrm{n}(\%)$} & \multicolumn{3}{|c|}{ In SPDC n (\%) } & \multicolumn{3}{|c|}{ At discharge $n(\%)$} \\
\hline & Overall & Females & Males & Overall & Females & Males & Overall & Females & Males \\
\hline Benzodiazepine & $960(58.6)$ & $513(42.3)^{*}$ & $447(35.5)^{*}$ & $1927(79.3)$ & $964(79.4)$ & $963(76.6)$ & $1604(68.0)$ & $795(65.5)$ & $809(64.3)$ \\
\hline $\begin{array}{l}\text { Atypical } \\
\text { antipsychotic }\end{array}$ & $700(42.7)$ & $321(26.4) \dagger$ & $379(30.1) \dagger$ & $1215(50.0)$ & $571(47.0) \dagger$ & $644(51.2) \dagger$ & $1222(51.8)$ & $577(47.5)$ & $645(51.3)$ \\
\hline $\begin{array}{l}\text { Conventional } \\
\text { antipsychotic }\end{array}$ & $690(42.1)$ & $316(26.6) \dagger$ & $374(29.7) \dagger$ & $1268(52.2)$ & $575(47.4)^{*}$ & $693(55.1)^{*}$ & $1046(44.4)$ & $483(39.8) \dagger$ & $563(44.8) \dagger$ \\
\hline Antidepressant & $591(36.1)$ & $36 \mid(29.7)^{*}$ & $230(18.3)^{*}$ & $808(33.3)$ & $476(39.2)^{*}$ & $332(26.4)^{*}$ & $795(33.7)$ & $464(38.2)^{*}$ & $33 \mid(26.3)^{*}$ \\
\hline Mood stabilizer & $509(31.1)$ & $263(21.7)$ & $246(19.6)$ & $764(31.5)$ & $391(32.2)$ & $373(29.7)$ & $774(32.8)$ & $392(32.3)$ & $382(30.4)$ \\
\hline Anticholinergic & $13 \mid(8.0)$ & $53(4.4) \dagger$ & $78(6.2) \dagger$ & $301(12.4)$ & $119(9.8)^{*}$ & $182(14.5)^{*}$ & $261(11.1)$ & $107(8.8) \S S$ & $\begin{array}{c}154 \\
(12.2) \S S\end{array}$ \\
\hline Other & $67(4.1)$ & $28(2.3) \dagger$ & $15(1.2) \dagger$ & $215(8.9)$ & $92(7.6)^{*}$ & $55(4.4)^{*}$ & I0I (4.2) & $43(3.5) \dagger$ & $24(1.9) \dagger$ \\
\hline $\begin{array}{l}\text { Total no. of } \\
\text { patients on } \\
\text { treatment } \\
\text { (\% of total PERSEO } \\
\text { population) }\end{array}$ & $1638(66.3)$ & $825(68.0)$ & $813(64.6)$ & $2429(98.3)$ & II 97 (98.6) & $1232(97.8)$ & $2358(95.4)$ & $|16|(95.6)$ & $1197(95.2)$ \\
\hline
\end{tabular}

*Males versus females, $\mathrm{p}<0.00 \mathrm{I}$; †males versus females, $\mathrm{p}<0.05$; @males versus females, $\mathrm{p}<0.0 \mathrm{I}$ 

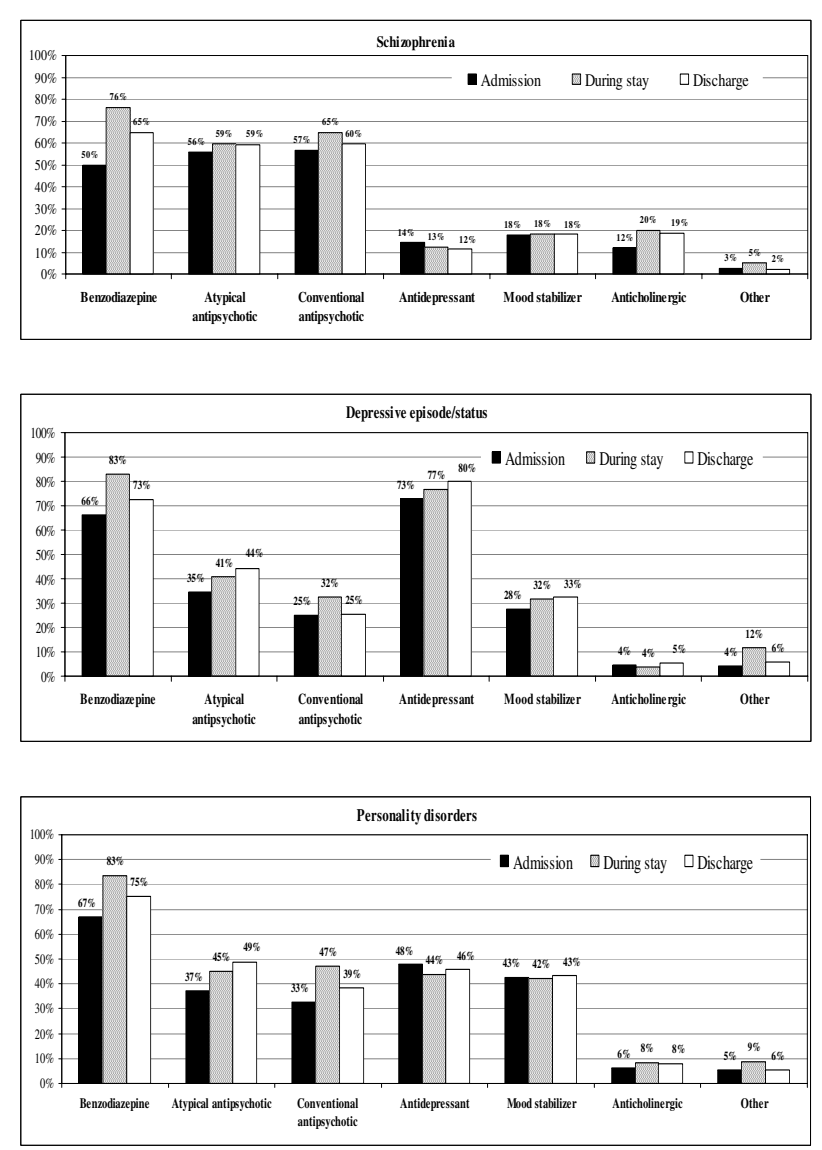

Figure I

Psychopharmacological therapies prescribed at admission, during stay and at discharge from SPDC for main $(n=100)$ psychiatric diagnoses (schizophrenia, depressive episode/status, personality disorders). Percentages are calculated on patients with at least one psychoactive drug prescribed within each diagnostic group. A patient could be taking more than one drug at the same time. Schizophrenia includes paranoid status and other nonorganic psychoses.

\section{Discussion}

PERSEO is a naturalistic, observational study aimed at assessing the epidemiological and clinical characteristics of patients admitted to Italian psychiatric units, including sociodemographic features and life habits, diagnoses, behaviours, and psychiatric symptoms at presentation, as well as their clinical management, subjective wellbeing and attitudes toward medications. To our knowledge, with 62 SPDC involved and 2521 cases enrolled, the PERSEO study represents the largest epidemiological survey performed in recent years on patients admitted to Italian psychiatric emergency structures.
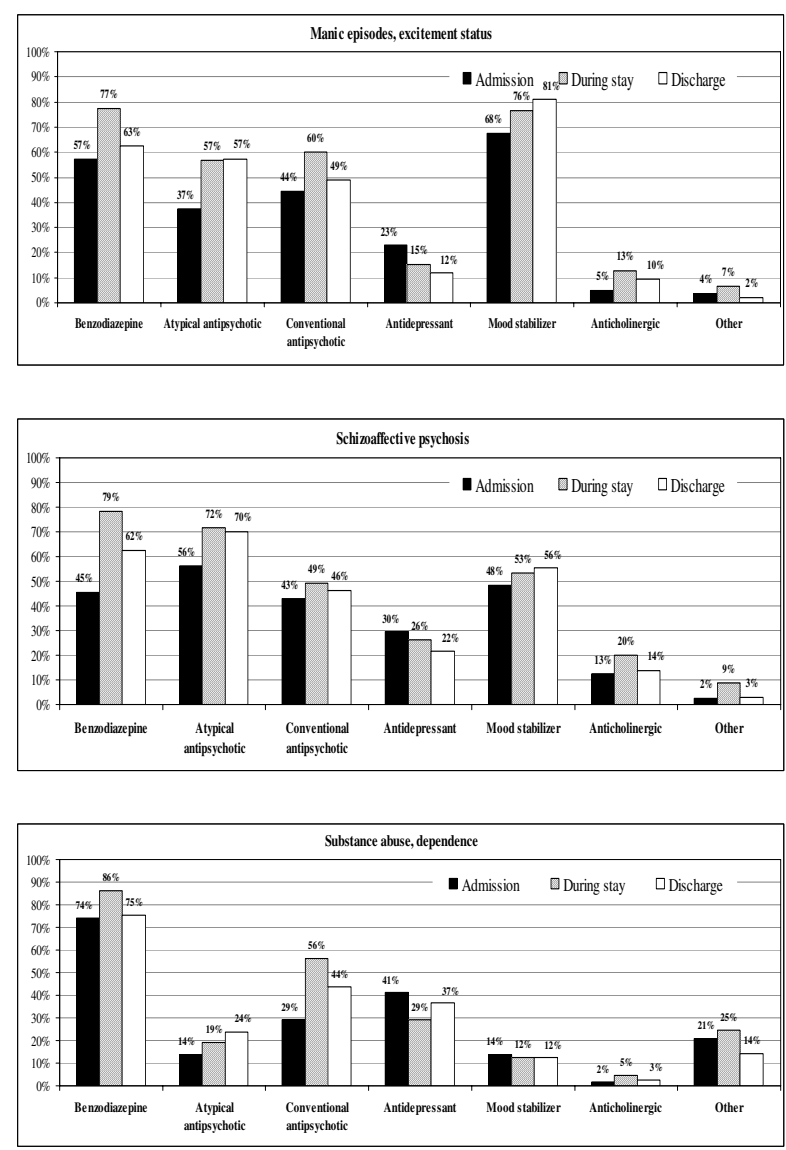

Figure 2

Psychopharmacological therapies prescribed at admission, during stay and at discharge from SPDC for main $(n=100)$ psychiatric diagnoses (manic episodes/excitement status, schizoaffective psychosis, substance abuse/dependence). Percentages are calculated on patients with at least one psychoactive drug prescribed within each diagnostic group. A patient could be taking more than one drug at the same time. Schizophrenia includes paranoid status and other non-organic psychoses.

Males and females were equally represented in our study population, but a statistically significant difference was observed between genders for all of the demographic characteristics (age, life habits, marital and occupational status), with females being on average 4 years older than males. This seems to be consistent with the delayed onset of psychosis in females as compared to males previously reported by several authors, in particular for schizophrenia, which has been explained by some authors by the role played by estrogens in modulating serotoninergic function [11-13]. The percentage of smokers was quite high in our patient population (57.5\%), but this was expected, as it is well known that psychiatric patients are more vulnerable to nicotine-dependence and rates of smoking are 
Table 5: Mean score $( \pm$ SD) at the subjective wellbeing (SWN) scale and number (\%) of patients with positive DAI-30 score at admission to and discharge from SPDC, in patients treated with antipsychotics (atypical, conventional or both)

\begin{tabular}{lccc}
\hline Rating scale & $\begin{array}{c}\text { Atypical } \\
\text { group }\end{array}$ & $\begin{array}{c}\text { Conventional } \\
\text { group }\end{array}$ & $\begin{array}{c}\text { Mixed } \\
\text { group }\end{array}$ \\
\hline SWN & & & \\
Admission & $73.1(17.4)$ & $76.0(19.0)$ & $74.6(18.2)$ \\
Discharge & $79.8(16.4)$ & $83.4(15.9)$ & $84.5(14.9)$ \\
DAl-30>0 & & & $169(67.6)$ \\
Admission & $249(68.8)$ & $212(64.2)$ & $197(78.8)$ \\
Discharge & $292(80.7)$ & $259(78.5)$ & \\
\hline
\end{tabular}

SWN: possible scores range from 20 to 120 , with higher scores indicating greater wellbeing. DAl-30: a score $>0$ indicates a positive attitude toward pharmacological treatments.

about two- to fourfold higher in patients with psychiatric disorders [14-16]. Conversely, the percentage of drug abusers was quite low, even though it has been reported that the prevalence of comorbidity of psychosis and substance abuse has been rising during the last $10-20$ years and substance use disorders are overrepresented in subjects with schizophrenia and bipolar and bipolar spectrum disorders [17-19]. Consistent with literature reports [20-22], the prevalence of smokers, drug or alcohol abusers in males was statistically higher than in females. Voluntary admissions to SPDCs were statistically higher for females than males.

Both at admission to SPDC and at discharge, the most frequent diagnosis was schizophrenia, followed by depression and personality disorders; interestingly, there were no relevant changes in diagnosis during hospital stay, indicating that patients' mental disorders had already been well recognized before unit admission. However, during SPDC stay psychiatric diagnoses were also defined for almost all patients admitted without diagnosis, with $97.4 \%$ of the overall patient population diagnosed at discharge.

It has been known for some time that psychiatric patients, in particular those affected with schizophrenia, are likely to engage in acts of aggression [23-25], but the importance of distinguishing among different types of aggression has been recently underlined [26]. Many of our patients showed some type of aggressive behaviour $(46 \%)$, but they engaged in verbal aggressive episodes more commonly $(38 \%)$ than in aggression against other people $(21 \%)$. As per diagnosis, the most frequent diagnosis among aggressive patients was schizophrenia, as already reported in another Italian study by Grassi et al [27]. The same study reported that most violent patients had had previous psychiatric admissions (92\%). However, it was shown that no difference in aggressive behav- iours emerges when comparing our results from the overall PERSEO population with those reported by Ballerini et al in the subgroup of patients at their first psychiatric admission [4].

Comparing the treatments prescribed during hospital stay and at discharge with those received by the patients before admission, the most commonly prescribed drugs were benzodiazepines, independent from psychiatric diagnosis or presence of aggressive behaviours, at all time points. Benzodiazepine prescription was statistically higher in women than in men at admission, but this difference disappeared during hospitalization and at discharge, with a global increase of use in both genders. Antidepressants, as expected, were most frequently prescribed for depressive episode/status and neurotic disorders. The most relevant change in psychopharmacological therapies observed after admission to an SPDC was the increase in administration of both atypical and conventional antipsychotics. Up to $83 \%$ of patients were prescribed neuroleptic drugs, and $27 \%$ had a combination of them. These percentages are not in disagreement with those reported by previous Italian surveys on the use of neuroleptics and other psychotropic drugs in Italian mental health services over the last decade, with $84 \%$ of neuroleptics prescriptions among psychiatric inpatients (up to $98 \%$ among schizophrenics) and $67-75 \%$ among outpatients, with 45 and $28 \%$ of combination therapies in in- and outpatients being reported, respectively [28-30]. The rates of prescription of conventional and atypical antipsychotics were quite similar at admission and during SPDC stay, whereas atypical antipsychotics were slightly preferred as a discharge prescription (Table 4). In particular, atypical and conventional antipsychotics were equally prescribed for schizophrenia (Figure 1), while atypical drugs were preferred in the other diagnostic groups, such as personality disorders (Figure 1), schizoaffective psychoses or affective psychoses with manic or even depressive episodes (Figure 2 ). These data confirm the increasing use of atypical antipsychotics reported in several American and Italian pharmaco-epidemiological studies [31-34] over the last decade, even though they also seem to indicate that conventional antipsychotics are not being completely replaced in clinical practice by modern "atypical " antipsychotics, as commented by Gardner et al in a very recent critical overview [34]. Differences in drug prescription observed between males and females reflect the different diagnosis distributions observed. The percentage of patients receiving combination therapies was quite high at all time points, thus confirming the widespread use of polypharmacy, a pattern that seems to have grown considerably over the last three decades $[28,30,35]$, despite remaining controversial. Many new drugs are available nowadays, and physicians might be motivated to consider polypharmacy in an attempt to improve quality of life and 
increase efficacy, but some authors have underlined that polypharmacy can also increase the risk of adverse effects, drug interactions, non-compliance, and medication errors [36].

If we compare discharge prescriptions in first psychiatric admission (FPA) patients, as analysed in our previous report [4], with non-FPA patients, no significant differences are observed: benzodiazepines (69\% of FPA patients; 69\% of non-FPA patients), atypical (in 51 and $53 \%$ of patients respectively) and conventional antipsychotics (in 38 and $46 \%$ of patients respectively) were the most prescribed drugs for both populations, with schizophrenia being the commonest diagnosis in both groups (31\% among FPA patients, 35\% in non-FPA patients). By contrast, mood stabilizers were given in a significantly lower proportion of FPA cases $(21 \%$ vs $35 \%$ of non-FPA cases; $\mathrm{p}<0.001$ with Bonferroni correction for five multiple comparisons), whereas a higher though not significant percentage of antidepressants $(41 \%)$ were prescribed to FPA than to non-FPA patients ( $34 \% ; \mathrm{p}=0.2$ with Bonferroni correction for five multiple comparisons).

An increase in self-referred compliance was observed from admission to SPDC to discharge, indicating that our patient population's subjective view of drug treatment became more positive during hospital stay.

\section{Conclusion}

We are aware that this survey suffers from the limitations of a naturalistic, observational, non-comparative, nonrandomised design; however it offers updated information on the clinical characteristics and management of a considerable population of patients admitted to psychiatric emergency structures spread throughout Italy. With regard to medications, our results confirm the widespread use of antipsychotics and the increasing trend in atypical drug prescription, for both psychiatric in- and outpatients. Positive data emerged regarding patients' perception of treatment, a measure that is increasingly considered crucial to improve the use of psychotropic drugs and enhance medication adherence, which might eventually relate to the clinical outcome of the disease $[34,35]$.

\section{Competing interests}

The study was fully sponsored by Eli Lilly Italy. SF, AR and MS are current employees of Eli Lilly Italy.

\section{Authors' contributions}

$\mathrm{AB}, \mathrm{RB}, \mathrm{GB}, \mathrm{MC}, \mathrm{FM}, \mathrm{LM}, \mathrm{RR}, \mathrm{FR}$ and $\mathrm{AS}$ are members of the PERSEO study Advisory Board. They all contributed to the study protocol design, enrolment, and interpretation of analyzed data and to the review of this paper. SF, AR, MS are current employees of Eli Lilly Italy, the study sponsor. They contributed to the interpretation of analyzed data and to the writing and review of this paper. Finally, the members of the PERSEO study group contributed to patient's enrolment.

\section{Appendix}

The PERSEO study group

The following centers have collaborated on the PERSEO study:

- Barale F, Bonzano A, Scioli R - Neurol. Inst. of Mondino Pavia

- Bellomo A, De Giorgi A, Cammeo C - Osp. Riuniti Hospital Foggia

- Cao A, Zara B - San Francesco Hospital Nuoro

- Conforti I, Chillemi C - Psychiatric Department Parma

- Dagnino L, Ponzoni M - Ospedali Riuniti Hospital Bergamo

- Della Pietra F, Benettazzo M - Azienda USL 16 Hospital Padova

- Esposito V, Sposito M - Psychiatric Department Palermo

- Fato M, Signorello G - Hospital department of Ponente Genova

- Fiorenzoni S, Singali A - Ponte Nuovo Hospital Firenze

- Margari F, Sicolo M - Policlinico Consorziale Hospital Bari

- Martino C, Leria G - Santa Croce Hospital Torino

- Tavolaccini L, Nigro G - Martini Hospita ITorino

- Russo V, La Rovere R - SS. Immacolata Hospital Chieti

- Righi R, Mazzo M - Hospital of Adria Rovigo

- Rocchetti R, De Martiis L - Umberto I Hospital Ancona

- Rodighiero S, Morello M - Hospital of Monselice Padova

- Vescera M, Pisciotti DG - Iannelli Hospital Cosenza

- Villari V, Barzegna G - Molinette S. G. Battista Hospital Torino

- Annicchiarico V, Cosmai MG - Hospital of Venere Bari 
- Rossi G, Baraldi EC - Poma Hospital Mantova

- Casacchia M, Ruggiero D - San Salvatore Hospital L'Aquila

- Galimberti P, Fellini FA - Angelucci Hospital Roma

- Francobandiera G - Civil Hospital Sondrio

- Gaspari D, Turati D - SSS. Trinità Hospital Novara

- Matacchieri B, Moscati G - Hospital Taranto

- Mautone A, Casale M - Hospital of Sant'Arsenio Salerno

- Mellado C, Scaramelli B - L. Sacco Hospital Milano

- Filippo A, Miccichè M - Beato Angelo Hospital Cosenza

- Minervini L, Banzato C - Azienda USL 16 Hospital Padova

- Orengo S, Alisio G - San Paolo Hospital Savona

- Picci RL, Venturello S - S. Luigi Gonzaga Hospital Torino

- D'Aloise A, Vaira F - S. Timoteo Hospital Campobasso

- Boccalon RM, Cavrini L - Sant' Anna Hospital Ferrara

- Cogrossi S, Prato K - Osp. Maggiore Hospital Cremona

- Cremonese C, Menardi A - Azienda Hospital Padova

- Parisi M, Mentastro C - Umberto I Hospital Enna

- Prosperini P, Binda V - Magg. della Carità Hospital Novara

- Romano G, Materzanini A - Mellino Mellini Hospital Brescia

- Crudele A, Stella G - Hospital of Barletta Bari

- Petio C, Fuà B - Ottonello Institute Bologna

- Laich L, Miori M - Hospital department of Arco Trento

- Salteri A, Catania G - Vimercate Civil Hospital Milano

- Achena M, Fara FM - Hospital of Sassari Sassari

- Padoani W, Compagno S - Hospital of Conegliano Treviso
- Ballerini A, Pecchioli S, Moretti S - S.M.N. Hospital Firenze

- Bacchi L, Vicari E - Hospital of Partinico Palermo

- Arvizzigno C, Minunni P - F. Iaia Hospital Bari

- Rossi E, Zaiti MF - L. Pierantoni Hospital Forlì Cesena

- Boncompagni G, Selleri MS - O. Malpighi Hospital Bologna

- Minnai GP, Loche AP - San Martino Hospital Oristano

- Russo F, Antonucci A - Nuovo R. Margherita Hospital Roma

- Chiurco L, Amendola R - G. Compagna Hospital Cosenza

- De Giovanni MG, Martano A - V. Fazzi Hospital Lecce

- Borsetti G, Santone G - Umberto I Hospital Ancona

- Pettolino AR, Lisanti F - Umberto I Hospital Foggia

- Parodi A, Ciammella L, Botto G - Villa Scassi Hospital Genova

- Gillotta S, Florio G - Cannizzaro Hospital Catania

- Fiore F, Santangelo E - A. Landolfi Hospital Avellino

- Fucci G, Ricci M - Psychiatric Department Ravenna

- Ciaramella A, Della Porta A - S. Sebastiano M. Hospital Roma

- Sittinieri M, D'Asta L - Paternò Arezzo Hospital Ragusa

- Triolo S, Spatola A - ARNAS Civil Hospital Palermo

- Frediani S, Rossi A, Macchi S, Giovannini L, Germani S, Fabbri L - Eli Lilly Italia, Florence, Italy

- Fiori G (project leader), Sala S (clinical project manager assistant), Sgarbi S (clinical project manager), Simoni L (statistics), Zanoli M (clinical data manager) - MediData Studi e Ricerche s.r.l; c/o Centro Servizi CittàNova Viale Virgilio 54/U, 41100 MODENA, Italy.

\section{Acknowledgements}

This study was fully supported by an educational grant issued by Eli Lilly, Italy. The authors thank MediData for project management, statistical analyses and medical writing, and Stefania Germani for her support in the study management. 
Written informed consent for study participation and possible publication of study results was obtained from patients or their relatives.

\section{References}

I. Mosher LR: Italy's revolutionary mental health law: an assessment. Am J Psychiatry 1982, I39:199-203.

2. Margari F, Matarazzo R, Casacchia M, Roncone R, Dieci M, Safran S, et al.: Italian validation of MOAS and NOSIE: a useful package for psychiatric assessment and monitoring of aggressive behaviours. Int J Methods Psychiatr Res 2005, I 4: I09-I I8.

3. Ballerini A, Boccalon RM, Boncompagni G, Casacchia M, Margari F, Minervini L, Righi R, Russo F, Salteri A, Frediani S, Rossi A, Germani S, Fiori G, Sgarbi S, Simoni L: Lo studio PERSEO: evoluzione di un'indagine sui servizi psichiatrici di diagnosi e cura italiani. obiettivi e metodologia. Giornale Italiano di Psicopatologia 2006, 1 2:20-30.

4. Ballerini A, Boccalon RM, Boncompagni G, Casacchia M, Margari F, Minervini L, Righi R, Russo F, Salteri A, Frediani S, Rossi A, Scatigna $M$ : Main clinical features in patients at their first psychiatric admission to Italian acute hospital psychiatric units. The PERSEO study. BMC Psychiatry 2007, 7:3.

5. Ventura J: Training and quality assurance with the Brief Psychiatric Rating Scale: 'the Drift Busters'. Int J Methods Psychiatr Res 1993, 3:221-224.

6. Derogatis LR, Melisaratos N: The Brief Symptom Inventory: an introductory report. Psychol Med 1983, I3:595-605.

7. Naber D: A self-rating to measure subjective effects of neuroleptic drugs, relationship to objective psychopathology, quality of life, compliance and other clinical variables. Int Clin Psychopharmacol 1995, I0(Suppl 3): I33-188.

8. Hogan TP, Awad AG, Eastwood R: A self report scale predictive of drug compliance in schizophrenics: reliability and discriminative validity. Psychol Med 1983, I3:177-183.

9. Kay SR, Wolkenfield F, Murrill LM: Profiles of aggression among psychiatric patients. I. Nature and prevalence. J Nerv Ment Dis 1988, I 76:530-546.

10. Yudofski SC, Silver JM, Jackson W, Endicott J, Williams D: The Overt Aggression Scale for the objective rating of verbal and physical aggression. Am J Psychiatry 1986, I43:35-39.

II. Szymanski S, Lieberman JA, Alvir JM, Mayerhoff D, Loebel A, Geisler $S$, et al: Gender differences in onset of illness, treatment response course, and biologic indexes in first-episode schizophrenic patients. Am J Psychiatry 1995, I 52:698-703.

12. Joffe H, Cohen LS: Estrogen, serotonin, and mood disturbance: where is the therapeutic bridge? Biol Psychiatry 1998, 44:798-8II.

13. Hafner H: Gender differences in schizophrenia. Psychoneuroendocrinology 2003, 28(Suppl 2): I7-54.

14. Lasser K, Boyd JW, Woolhandler S, Himmelstein DU, McCormick D, Bor DH: Smoking and mental illness: a population-based prevalence study. JAMA 2000, 284:2606-2610.

15. Salin-Pascual RJ, Alcocer-Castillejos NV, Alejo-Galarza G: Nicotine dependence and psychiatric disorders. Rev Invest Clin 2003, 55:677-693.

16. Kalman D, Morissette SB, George TP: Co-morbidity of smoking in patients with psychiatric and substance use disorders. Am J Addict 2005, I 4:106-123.

17. Gouzoulis-Mayfrank E: Dual diagnosis of psychosis and addiction. From principles to practice. Nervenarzt 2004, 75:642-650.

18. Levin FR, Hennessy G: Bipolar disorder and substance abuse. Biol Psychiatry 2004, 56:738-748.

19. Tsuang J, Fong TW: Treatment of patients with schizophrenia and substance abuse disorders. Curr Pharm Des 2004, I 0:2249-226I

20. Bloor $\mathrm{R}$ : The influence of age and gender on drug use in the United Kingdom - a review. Am J Addictions 2006, I 5:201-207.

21. Skorge TD, Eagan TM, Eide GE, Gulsvik A, Bakke PS: Exposure to environmental tobacco smoke in a general population. Resp Med 2007, I 0 I:277-285

22. Dawson DA: Gender differences in the probability of alcohol treatment. J Substance Abuse 1996, 8:21 I-225.

23. Rossi AM, Jacobs M, Monteleone M, Obsen R, Surber RW, Winkler EL, Wommack A: Violent or fear-inducing behavior associated with hospital admission. Hosp Community Psychiatry 1985, 36:643-647.
24. Pearson $M$, Wilmot $E$, Padi M: A study of violent behaviour among in-patients in a psychiatric hospital. Br J Psychiatry 1986, I 49:232-235.

25. Tardiff K, Marzuk PM, Leon AC, Portera L: A prospective study of violence by psychiatric patients after hospital discharge. Psychiatr Serv 1987, 48:678-68I.

26. Troisi A, Kustermann S, Di Genio M, Siracusano A: Hostility during admission interview as a short-term predictor of aggression in acute psychiatric male inpatients. J Clin Psychiatry 2003, 64:|460-1464.

27. Grassi L, Peron L, Marangoni C, Zanchi P, Vanni A: Characteristics of violent behaviour in acute psychiatric in-patients: a 5-year Italian study. Acta Psychiatr Scand 200I, I 04:273-279.

28. Tibaldi G, Munizza C, Bollini P, Pirfo E, Punzo F, Gramaglia F: Utilization of neuroleptic drugs in Italian mental health services: a survey in Piedmont. Psychiatr Serv 1997, 48:213-217.

29. Tognoni G: Pharmacoepidemiology of psychotropic drugs in patients with severe mental disorders in Italy. Italian Collaborative Study Group on the Outcome of Severe Mental Disorders. Eur J Clin Pharmacol 1999, 55:685-690.

30. Magliano L, Fiorillo A, Guarneri M, Marasco C, De Rosa C, Malangone C, et al.: Prescription of psychotropic drugs to patients with schizophrenia: an Italian national survey. Eur J Clin Pharmacol 2004, 60:513-522.

31. Centorrino F, Eakin M, Bakh WM, Kelleher JP, Goren J, Salvatore P, Egli S, Baldessarini RJ: Inpatient antipsychotic drug use in 1993, and 1989. Am J Psychiatry 1998, 159:1932-1935.

32. Tempier RP, Pawliuk NH: Conventional, atypical, and combination antipsychotic prescriptions: a 2-year comparison. J Clin Psychiatry 2003, 64:673-679.

33. Trifiro G, Spina E, Brignoli O, Sessa E, Caputi AP, Mazzaglia G: Antipsychotic prescribing pattern among Italian general practitioners: a population-based study during the years 19992002. Eur J Clin Pharmacol 2005, 6 I:47-53.

34. Gardner DM, Baldessarini RJ, Waraich P: Modern antipsychotic drugs: a critical overview. CMAJ 2005, I72: I703-I7II.

35. Rittmannsberger $\mathrm{H}$ : The use of drug monotherapy in psychiatric inpatient treatment. Prog Neuropsychopharmacol Biol Psychiatry 2002, 26:547-55I.

36. Ananth J, Parameswaran S, Gunatilake S: Antipsychotic polypharmacy. Curr Pharm Des 2004, 10:223 I-2228.
Publish with Biomed Central and every scientist can read your work free of charge

"BioMed Central will be the most significant development for disseminating the results of biomedical research in our lifetime. "

Sir Paul Nurse, Cancer Research UK

Your research papers will be:

- available free of charge to the entire biomedical community

- peer reviewed and published immediately upon acceptance

- cited in PubMed and archived on PubMed Central

- yours - you keep the copyright
BiolMedcentral 